\title{
Adolescência, atos e o risco de suicídio
}

\author{
Carolina Nassau Ribeiro* (1) \\ Andréa Maris Campos Guerra \\ Universidade Federal de Minas Gerais, Pós-Graduação em Psicologia. Belo Horizonte, MG, Brasil
}

Resumo: Este artigo discute o problema do risco do suicídio na adolescência, utilizando a série Os 13 porquês como recurso metodológico para decantar o que está em jogo na relação entre a adolescência, os atos e o risco de suicídio. Para compreender mais profundamente o tema, as autoras realizam uma leitura da adolescência a partir do referencial teórico da psicanálise de Freud e Lacan, ressaltando a tendência ao agir da adolescência e os comportamentos de risco característicos dessa etapa da vida. O texto traça, ainda, uma distinção entre acting out e passagem ao ato, e propõe uma discussão sobre o manejo clínico do analista que escuta uma ideação suicida de um adolescente.

Palavras-chave: adolescência, suicídio, psicanálise, acting out, passagem ao ato.

\section{Introdução}

A série $O s 13$ porquês lança luz sobre a instigante e muitas vezes silenciada questão do suicídio na adolescência. A relevância do tema é inegável, e os dados revelam um aumento considerável do número de suicídios e tentativas de autoextermínio que merece ser destacado. No mundo, 800 mil pessoas tiram a própria vida por ano, sendo essa a segunda maior causa mortis, nos últimos anos, entre jovens de 15 a 29 anos (UN News, 2018).

No Brasil, os dados notificados giram em torno de 11 mil pessoas por ano, sendo o suicídio computado como a quarta maior causa mortis entre jovens de 15 a 29 anos no país ${ }^{1}$. Entre homens dessa faixa etária, é a terceira maior causa e, entre mulheres, a quinta. Não obstante, apesar de os homens terem uma taxa de suicídio maior que as mulheres, elas cometem a tentativa de suicídio em maior número que eles. Entre 2011 e 2016, 69\% das tentativas de suicídio aconteceram entre mulheres e $31 \%$, entre os homens. As mulheres são mais reincidentes na tentativa, mas os homens morrem mais. A taxa de mortalidade entre homens é 3,6 vezes maior que entre mulheres.

Vale destacar ainda que, no estado de Minas Gerais, de acordo com a matéria publicada no jornal Hoje em Dia no dia 18 de abril de 2017, as tentativas de suicídio entre adolescentes vêm aumentando: "os dados da Secretaria de Estado de Saúde (SES-MG) revelam que, de 2010 a 2016, o número de pessoas entre 15 e 19 anos que tentaram se matar no estado cresceu 15 vezes" 2 . Como podemos verificar nos dados mencionados,

\footnotetext{
* Endereço para correspondência: carolnassau@gmail.com

1 Recuperado de https://bit.ly/3mmldUe

2 Recuperado de https://bit.ly/2R41kCX
}

então, a faixa etária entre 15 e 29 anos de idade pode ser considerada de grande vulnerabilidade para o risco de suicídio. Trata-se, portanto, de tema que merece todo o nosso interesse.

Uma recente pesquisa publicada no The British Journal of Psychiatry (2019) sustenta que o tratamento psicanalítico e as psicoterapias são as mais eficazes na redução das tentativas de suicídio, apesar de não conseguir identificar quais elementos especificamente tornam essas psicoterapias mais efetivas. Este texto tem a ambição de tentar localizar como a psicanálise pode ter esse efeito.

Assim, ensejam-se, aqui, formulações teóricas na tentativa de responder às indagações do jornal inglês e contribuir para uma intervenção mais apurada no momento em que o jovem for socorrido ou procure alguém que possa escutá-lo. Para avançarmos nessa direção, utilizaremos a série Os 13 porquês (Yorkey, 2017) como recurso metodológico para decantar o que está em jogo na relação entre a adolescência e o risco de suicídio. Centrar-nos-emos, sobretudo, no único momento em que a jovem procura um conselheiro da escola para escutá-la. É possível escutar seus indícios? Há pistas e ameaças que possam prevenir o suicídio? Há o que fazer? E, se sim, o que é possível fazer?

\section{Adolescência e riscos}

Antes de iniciarmos nosso debate sobre a adolescência, é importante destacar que este nem sempre foi um tema sobre o qual psicanalistas se debruçaram, ainda que Freud tenha se dedicado a uma vasta clínica com jovens histéricas e escrito um texto avant garde em seu tempo, em 1905, no qual problematiza os impasses, tão atuais ainda, que a puberdade suscita. Freud, entretanto, raramente utilizou o termo "adolescência". 
Ao falar sobre esse assunto, ele aludiu mais à puberdade do que à adolescência propriamente dita. Lacan também fez raras alusões à adolescência, sendo a mais famosa delas o comentário sobre a peça de Wedekind (1891/2009), O despertar de primavera: uma tragédia infantil e MineHaha, ou Sobre a educação corporal das meninas, que desfia, já no final do século XIX, vários dos conflitos e riscos aos quais os adolescentes continuam expostos, dentre eles o suicídio.

A concepção de adolescência como período intermediário entre a infância e a idade adulta surgiu no século XIX e, desde então, só vem ganhando força, a ponto de falarmos de um prolongamento das características dos adolescentes para além dos 30 anos de idade. Alguns autores sustentam, inclusive, a tese de que estamos vivendo em uma sociedade adolescente (Le Breton, 2017).

Para Le Breton (2017), a adolescência é atravessada pelo tempo e pelo espaço das sociedades e, por esse motivo, sua cronologia não é bem delimitada: "A adolescência tem se tornado cada vez mais precoce e comportamentos qualificados de 'adultescentes' atingem jovens que, algumas vezes, já ultrapassaram em larga medida os trinta anos" (p. 21).

Ainda para este autor, a adolescência seria o tempo de o jovem construir "a questão do sentido e do valor de sua existência" (Le Breton, 2017, p. 22). Trata-se de uma construção árida e solitária no contexto do individualismo democrático em que o adolescente não tem mais rituais de passagem que balizem a construção de um papel social que dê um sentido a sua existência e também não possui um saber social construído que ampare esse tempo de suspensão das significações da infância. Não por acaso, ousamos afirmar que o trabalho clínico com adolescentes porta um risco significativo, já que o valor e sentido de sua existência estão sendo colocados à prova.

O tema do suicídio na adolescência, apesar de sempre contemporâneo, não é novo. Há mais de cem anos, essa questão aflige pais, educadores, profissionais da saúde e psicanalistas. Freud (1910/1974), em uma reunião na Sociedade Psicanalítica de Viena, após a fala de um educador, faz uma breve reflexão sobre o suicídio dos jovens nas escolas, posteriormente publicada no pequeno texto que hoje conhecemos sob o título de "Contribuições para uma discussão acerca do suicídio". Nota-se que o que estava sendo discutido naquele momento, ou seja, há mais de um século, é, portanto, facilmente relacionável com a temática da série à qual fazemos alusão - o suicídio de jovens. Uma das perguntas levantadas pela série, como veremos a seguir, é exatamente até que ponto a escola e seus procedimentos têm alguma relação com o suicídio de seus alunos.

É curioso que Freud deixe em suspenso na breve discussão as implicações psíquicas do suicídio e destaque em seu comentário o papel da escola neste processo. Para ele, a escola não impele o jovem a este ato: "Não nos deixemos levar longe demais" (Freud, 1910/1974, p. 217).
Não obstante, ele não a exime de fracassar no sentido de contribuir para o desenvolvimento do desejo dos jovens pela vida:

Mas uma escola secundária deve conseguir mais do que não impelir seus alunos ao suicídio. Ela deve lhes dar o desejo de viver e devia lhes oferecer apoio e amparo numa época da vida em que as condições de seu desenvolvimento as compelem a afrouxar seus vínculos com a casa dos pais e com a família. Parece-me indiscutível que as escolas falham nisso, e a muitos respeitos deixam de cumprir seu dever de proporcionar um substituto para a família e de despertarem um interesse pela vida e pelo mundo exterior. (Freud, 1910/1974, p. 218, grifos nossos)

Ele ressalta - e isso nos parece um ponto muito atual - a importância de a escola saber lidar com a possibilidade de os jovens se demorarem "em certos estágios do desenvolvimento e mesmo em alguns um pouco desagradáveis" (Freud, 1910/1974, p. 218). Não há a menor dúvida de que um estágio pouco agradável é a adolescência. Este é um período de mudanças, estranhamentos, distanciamentos, perdas e lutos, mas também de muitas conquistas. Como é possível verificar, há aqui o apontamento da responsabilidade da escola nesse momento perigoso de afrouxamento do vínculo com os pais.

Se esse afrouxamento é estrutural, isto é, necessário à passagem pela adolescência, há que se considerar uma mudança estatutária do lugar da família, correlata à contemporaneidade. Para Le Breton (2017), "A individualização do laço social contribuiu para a desinstitucionalização da família, que deixa de ser a célula elementar da sociedade para se tornar mais um refúgio sentimental, um lugar provisório, consensual, do entre pares" (p. 92). Como consequência, há uma mudança também do lugar da criança. Ela deixa de ser fruto de uma série de gerações sucessivas por onde a transmissão e a filiação se inscrevem ou, ainda, aquela submetida ao controle e à ordem parental, portadora da dimensão da autoridade, para tornar-se mais uma companheira de jornada, um dentre outros interesses, restando como objeto da instabilidade e provisoriedade das relações. Assim, resta a questão acerca de quem sustentará os impasses pulsionais emergentes no corpo adolescente.

Ora, podemos nos perguntar: para onde toda essa libido será agora redirecionada? Essa libido, que outrora estava vinculada a uma forte referência - ainda que imaginária - na infância, precisa de novos objetos para se relançar nessa nova etapa da vida. E essa busca não acontece sem errâncias, atos e riscos, dentre os quais está o de colocar em xeque a manutenção da própria vida.

Stevens (2004) considera que a adolescência é um sintoma da puberdade, ou seja, é uma resposta possível ao encontro impossível com o Outro sexo que emerge nesse momento. Dentre as respostas possíveis, 
destacaremos aquelas que consideramos relevantes para o tema em questão: afrouxamento dos vínculos com os pais (Freud, 1910/1974), período de elaboração de perdas e também da falta no campo do Outro (Alberti, 1996) e, também, de errâncias e riscos (Lacadée, 2011). Como se pode observar, trata-se de um momento profícuo para que os atos tomem o lugar da palavra e coloque o jovem errante em situações extremas e imprevisíveis.

Para Lacadée (2011), o adolescente está "apressado para encontrar o lugar e fórmula" - alusão à poesia de Rimbaud -, o que o coloca em uma relação peculiar com o tempo e com a intensidade da vida. Nesse sentido, sustentamos a tese, já aludida anteriormente, de que a adolescência implica uma clínica em que paira a pressão da urgência. Está além das possibilidades do adolescente esperar para concluir algo. Há muita pressa e precipitações.

Para esse autor, o adolescente interroga a morte para saber se vale a pena viver. Há jogo com a intensidade da vida por meio do relato de muitos riscos, atos e precipitações. Ao tratar da conduta de risco dos jovens, Lacadée (2011) avalia, tal como Le Breton (2009), que a ausência de referências tradicionais lançaria alguns jovens ao abandono, "obrigando-os a se tornarem os artesãos do sentido de suas existências" (Lacadée, 2011, p. 55). Daí as condutas de risco serem antes uma aposta na vida verdadeira que um ensaio para morrer. O corpo, morada onde se atualizam as questões da identidade e do gozo, o qual não encontra palavras para nomear, é o alvo na busca por limites não encontrados. Entretanto, enquanto Le Breton (2009) associa as condutas de risco aos ritos de passagem dos jovens na contemporaneidade, Lacadée problematiza essas condutas, enxergando-as sintomas contemporâneos nos quais o ato tem dimensão preponderante. Algumas dessas condutas assumiriam, ainda, a forma de "modos de vida" (Lacadée, 2011, p. 56). Essa posição coloca o adolescente como aquele que o adulto não só teme, como também já não mais reconhece a familiaridade com a criança que o jovem foi.

A adolescência é o momento lógico em que se opera a desconexão para o sujeito entre seu ser como criança e seu ser como homem ou mulher, no qual surge a dimensão do ato, de modo inédito, na ligação do sujeito com o seu corpo. Esse ato, à medida que engendra o novo, procura um lugar onde ser autenticado - "operação" essencial para o adolescente. (Lacadée, 2007)

Eé nesse momento lógico de desligar-se dos pais, procurar um lugar que o caiba, tentar ligar-se a um grupo, descobrir o que é seu e o que é de sua família, que o jovem experimenta o efeito de inquietação e contestação constante, de suspensão do sentido e valor da vida.

Se partirmos da concepção de Jacques Lacan de que as amarrações que acontecem entre os registros Real, Simbólico e Imaginário com um quarto elo podem favorecer uma organização psíquica nos sujeitos (Lacan, 1975-1976/2007), nesse caso, em pleno florescer da adolescência, podemos supor que encontramos uma irrupção do Real do sexo, uma alteração da imagem do corpo com sua incidência sobre o registro Imaginário e a criação de uma nova língua no campo Simbólico, que se traduz por gírias e códigos produzidos pelos adolescentes. Os efeitos dessa irrupção da adolescência sobre os registros Real, Imaginário e Simbólico promovem um desenlaçamento dos jovens com o que até então funcionava na infância, cujos efeitos podem culminar em certa desorientação e na sensação de que nada mais faz sentido (Nassau, Couto, Guerra, Capanema, \& Lima, 2018).

A criança, até então sustentada na promessa de que, ao preço de uma renúncia provisória, teria acesso ao verdadeiro gozo, depara-se com o fato de que, embora possa ter acesso à genitalidade, o objeto de seu desejo e o Outro não são reconciliados no ato sexual: o gozo sexual é parcial, e o real do fracasso o espreita. $\mathrm{O}$ aspecto catastrófico desse acontecimento é primário, e é sobre ele que o sujeito elabora respostas. (Vorcaro \& Capanema, 2011)

Testemunha-se, então, a fragilidade significante e o confronto com o real desvelarem a inconsistência do Outro. Os agenciadores simbólicos - significante mestre, significante fálico e nome-do-pai - se mostram enganadores, sendo abalados em sua função de articulação com os registros Real e Imaginário.

Nesse tempo de desamarração entre os três registros, o adolescente segue errando e errante, a procurar "o seu lugar e a sua fórmula". Assim, observamos vários comportamentos de risco nesse momento da vida (Calligaris, 2000; Erikson, 1968/1976). Dentre esses comportamentos, destacam-se o uso de drogas, tentativas de suicídio, transtornos alimentares, cortes no próprio corpo, sexo sem segurança e transgressões diversas. Trata-se, portanto, de uma violência que se traduz em atos que dão vazão àquilo que não cessa de se inscrever em seus corpos.

Para Lacadée (2007), fuga, errância e condutas de risco são elementos importantes na adolescência, pois repetem algo da ordem do gozo, do sem sentido, para tentarem se localizar. Nesse sentido, o jovem está em busca de algo que enlace os registros, que faça laço, e para isso precisa "inventar outros parceiros, outras cenas, outras comunidades da vida, outros lugares de traduções, e mesmo correr riscos, pôr sua vida em jogo" (Lacadée, 2013, p. 28). São, portanto, mais tentativas de viver do que de morrer.

O que é importante destacar, assim, é uma prevalência dos atos nesse período da vida. $\mathrm{O}$ adolescente tende ao ato, pois conclui muito rapidamente. Em sua pressa, ele não suporta experimentar o tempo de compreender. Discutiremos mais à frente a especificidade 
desses atos, mas adianta-se aqui a afirmação de que o ato pode vir como uma tentativa de resolver um impasse com o Outro, para dar vazão a uma experiência sobre a qual é impossível dizer (Lacadée, 2013, p. 19).

\section{Sobre a série: uma releitura e alguns comentários}

Hannah Baker ${ }^{3}$ é uma adolescente de 17 anos que cursa o ensino médio de uma escola norte-americana (High School) e vem de uma família que não parece diferente de muitas famílias. Não há nada excessivamente patológico naquela família ${ }^{4}$, eles apenas (e isso não é pouco) não conseguem prestar muita atenção na filha, apesar de nitidamente terem muito amor por ela. Estão às voltas com uma farmácia ${ }^{5}$ prestes a quebrar e simplesmente não veem a filha com olhos mais aguçados. Ela esboça seu sentimento de invisibilidade em relação a eles com uma fala muito contundente dirigida a Clay: "Os pais acham que não percebemos as coisas. Eles não só não me veem; eles não me veem vendo eles [sic]".

$\mathrm{Na}$ escola, Hannah sofre bullying e uma série de desencontros, tanto no campo das amizades como no campo afetivo, havendo, desde os primeiros episódios, uma discussão sobre o bullying virtual e seus efeitos. No primeiro episódio, Justin, o rapaz em quem dá seu primeiro beijo, tira uma foto dela descendo no escorregador e, por acaso, por um golpe de visão, sua calcinha aparece. A foto é cruelmente distribuída virtualmente pelos alunos da escola, e aquilo que havia sido apenas um beijo se torna um provável sexo no parque. A situação, em decorrência das mídias sociais, toma uma proporção bem maior do que o que realmente aconteceu entre eles.

A série, portanto, enfatiza muito esse tema da espetacularização da vida: na foto de Courtney e Hannah, duas amigas que se beijam, que circula pelos jovens da escola; na figura do perseguidor fotógrafo que sabe de tudo o que acontece e não só registra isso em fotos, como as publica no jornal da escola; na divulgação da poesia de Hannah no jornal da escola, que resulta em júbilo e zombaria de muitos. Tudo está muito exposto, muito visto, assim como acontece nos relatos dos adolescentes que atendemos em nossos consultórios ou nas instituições em que trabalhamos. Curiosamente, apesar dessa espetaculizaração da vida, a cegueira permeia as relações, e o sentimento de vazio, errância e invisibilidade aumenta em Hannah.

Ela, por seu turno, é impulsiva, tira conclusões precipitadas, como a grande maioria dos adolescentes. O mais complicado é que ela não endereça suas questões

3 Neste texto não será discutida a estrutura clínica de Hannah, o que, na prática clínica, pode contribuir muito para responder algumas das perguntas levantadas.

4 Na segunda temporada, descobrimos que os pais estavam passando por uma crise no casamento.

5 É dessa farmácia que Hannah retira os objetos que comporão seu ato final: as fitas, o esmalte que numera as fitas e a gilete. a ninguém que possa realmente escutá-la. É silenciosa e, curiosamente, tem poucas condutas de risco, faz muito pouco barulho. Esses são os adolescentes mais preocupantes, aqueles que não falam, que não endereçam suas queixas.

Algumas dessas experiências vão sendo apontadas na série nas sucessivas tentativas de Hannah de fazer laço, seguidas de sucessivos cortes e decepções. Nos capítulos iniciais, é exemplo disso a amizade triangular com Jéssica e Alex, que se desfaz quando os dois começam a namorar. Depois, observa-se a rápida intimidade com Courtney seguida de um corte brusco quando esta depara com a própria homossexualidade oculta revelada na foto em que as duas se beijam. Também é vivida a esperança de um encontro com Marcos, encerrada quando ele a aborda sexualmente de maneira mais violenta. É curioso notar como a lâmina do Real do sexo faz corte nas tentativas de laços que poderiam ser afetivos. Tudo muito líquido, para parafrasear Bauman (2007); tudo muito exposto e mediado por imagens, como previsto por Guy Debord (2003).

Entretanto, para quem está familiarizado com a clínica de adolescentes, não há nada, até o nono episódio, muito diferente do que acontece com a maioria dos pacientes. Em alguns momentos da série, perguntamo-nos se a principal questão a ser discutida ali seria bullying ou suicídio. Muitos personagens da vida e da série passam por situações similares àquelas vividas pela protagonista e não optam pelo suicídio. A personagem tatuada e cheia de piercings que trabalha no café afirma isso a Clay, mostrando seus cortes no braço: "É assim que a gente sobrevive" ${ }^{\prime \prime}$. Essa personagem revela como as intervenções corporais dos adolescentes são uma tentativa de fazer algo em resposta a uma experiência que não conseguem nomear ou compreender, mas que suscita neles a necessidade de produzir alguma marca que inscreva essa experiência.

A partir do episódio em que assiste muda e passiva a uma colega bêbada ser estuprada por Bryce, começam a aparecer em Hannah algumas posições que vão apontando para certo desligamento com a vida e, para usar os termos de Freud, um afrouxamento dos vínculos. Ela vai optando por não falar, por não se ligar, por não se endereçar a ninguém. Isso acontece primeiro na cena do estupro, em que ela não consegue se posicionar nem durante, nem depois, e se intensifica posteriormente. A ausência da fala aumenta e potencializa a densidade traumática do vivido, fixando Hannah em um lugar de imobilidade.

Na sequência, acontece um acidente de carro que causa a morte de um colega em decorrência da ausência de uma placa que fora derrubada em um incidente com o carro dirigido por Sheri (outra amiga), que vai embora

6 Trata-se da prática do cutting, também muito comum na adolescência, sobretudo em sujeitos do sexo feminino. Adeptos da prática afirmam que o cutting fornece alívio num momento de transbordamento de dor e de angústia. É como se o corte circunscrevesse certo limite para uma angústia ilimitada. Também verificamos uma saída pela via do ato, nesse caso um ato menos radical, que geralmente pode contar com intervenção de outro, já que pode ser visto em algum momento. 
sem notificar a polícia. Hannah sabia, estava presente no momento da queda da placa e, apesar de chamar a emergência, não denuncia o que está subjacente ao acidente automobilístico fatal. Ela tenta falar para Clay, mas ele está de luto, com raiva. Ela também não insiste, nunca insiste. Desistências sucessivas vão acontecendo. Sem dúvida, ela está em busca de alguém, de um endereço.

Mas como ela o faria se não se endereça a ninguém? Se não fala com ninguém que suporte os efeitos da fala? Somente a partir da fala é possível deslocar os sentidos, os significados e as significações rigidamente imbricadas na trama, ou a "treta" (para usar o termo dos adolescentes) que é a vida de cada um. E os pais? Ao que parece, como ela mesma diz, não conseguem vê-la.

$\mathrm{O}$ encontro com Clay, personagem apaixonado por ela, também é bem significativo. Apesar de desejá-lo loucamente, ela o repele. Não há como não ver ali algo da histeria. Ele, por sua vez, tenta, mais de uma vez, entender o que está acontecendo, acalmá-la do estado de irritação e agressividade em que se encontrava, mas ela não cede, apesar de esperar sua insistência. Ele sai impotente do quarto. E, mais uma vez, a lâmina cortante do Real do sexual, aquilo sobre o que os corpos dos adolescentes são invadidos e sobre o que eles pouco ou nada conseguem falar transformou o que poderia ser um encontro de amor num desencontro radical.

Por que não houve uma palavra posterior? Novas mensagens ou novas tentativas? Mais uma vez, evidencia-se como a lógica do adolescente é a do ato e da pressa. E do ver e concluir, antes de compreender. É dessa pressa, dessa urgência em concluir que se precipitam atos.

Entretanto um dos episódios mais perturbadores é aquele em que ela se dirige à casa de Bryce - o estuprador da amiga. Depois de perder o dinheiro dos pais (curiosamente para atender um telefonema de Clay, que não diz nada sobre eles, só sobre o trabalho), Hannah sai andando de modo errante pela cidade e para na porta de uma festa na casa daquele que havia violentado sua amiga sexualmente quando ela estava bêbada. E assim segue de modo errante para a hot tub, onde acaba sendo, igualmente e com mesmo silêncio petrificante, violentada.

O termo "errância" - tão enfatizado por Lacadée - descreve muito bem o modo como a maioria dos adolescentes agem quando estão angustiados sem saber como lidar com seus impasses, conflitos e falhas. Seguem em certa medida às cegas, sem pensar, uma tendência ao ato, e é exatamente por isso, por todos esses paradoxos e atos impulsivos e impensados, que a proposta deste artigo é discutir mais especificamente o último episódio da primeira temporada da série. É ali, já na beira do abismo, que se abre uma brecha para alguém entrar. Trata-se do momento em que Hannah procura o conselheiro da escola. Esse ponto nos concerne. O que é possível fazer nessa escuta mínima, nesse momento de risco, em que o sujeito pouco quer falar, mas se endereça a alguém?
A protagonista inicia o episódio com a seguinte afirmação: "Darei à vida uma última chance". Ao que parece, a experiência de gravar as fitas sobre os motivos que a conduziram para a passagem ao ato tiveram um efeito catártico para Hannah, que, então, resolve falar sobre o que lhe aconteceu, decidindo, finalmente, pedir ajuda. $\mathrm{O}$ atendimento se inicia bem, com a adolescente dando boas dicas ao conselheiro: sente-se perdida, vazia, como se nada mais importasse; precisa que a vida pare. Há aí um ponto fundamental: levar a fala do sujeito ao pé da letra, independentemente da estrutura clínica.

Contudo há algo que o conselheiro não suporta escutar. Lacan (1958/1998) nos diz que a resistência é sempre do analista. $O$ conselheiro não é analista, mas podemos pelo menos indagar o que ele resiste em escutar. Ele resiste em escutar o horror da violência sexual, num ponto de não aposta na palavra. Ele a convoca a prestar uma queixa (antes de escutá-la) ou seguir em frente. Há, então, uma explícita recusa de escuta cujos efeitos foram devastadores para esse sujeito já à beira de um abismo. Essa é a importância de uma escuta: dilatar o tempo de compreender entre o instante de ver e o momento de concluir para que o sujeito adolescente não se precipite em um ato como esse - o suicídio, que, para Lacan (1974/2003), é o único capaz de não falhar.

Nesse momento, o conselheiro da escola, em vez de escutá-la e desfiar os efeitos dessas experiências na sua vida, lhe dá um ultimato. Ele convoca a lei que rege os homens em vez de enlaçá-la para a ligação com a vida pela potência do simbólico de que a lei que rege o sujeito do desejo pode advir. Ela teria de denunciar o autor da violência sexual e arcar com seus efeitos ou seguir em frente silenciada. Ao assistir ao episódio, é muito nítido o recuo do personagem diante do impasse de bancar junto com Hannah uma possível denúncia, mas, sobretudo, antes disso, escutar o horror do que ela havia experimentado. Ser escutada era a única coisa que ela precisava naquele momento. Entretanto ele transforma aquele momento num protocolo a ser cumprido. Ora, o protocolo não dá um lugar para o sujeito (Miller \& Milner, 2006). É importante que primeiro ela se localize para depois ter condições de decidir sobre a possibilidade e as consequências de denunciar o colega legalmente.

Quando o conselheiro encerra a fala de Hannah na direção de uma conclusão, ao invés de dilatar o tempo de compreender, a situação culmina numa precipitação da protagonista, que passa ao ato. Ela sai da sala do conselheiro convencida de que não seria mais possível seguir em frente e, então, tira a própria vida.

Esse pequeno ponto, essa sutil passagem é de suma importância para o desenrolar da história de Hannah, pois ali havia um endereçamento antes do ato. Tendo então o problema do ato em vista, discutiremos a seguir brevemente sobre a diferença entre acting out e passagem ao ato, pois nos parece que essa distinção pode ser um norteador fundamental à clínica com adolescentes. 


\section{Os atos}

$\mathrm{Na}$ obra de Freud, encontramos pelo menos cinco termos para abordarmos a questão do ato ${ }^{7}$. Além disso, Freud nos diz que "o primeiro homem a desfechar contra seu inimigo um insulto, em vez de uma lança, foi o fundador da civilização. Portanto, as palavras são substitutas das ações e, em alguns casos (por exemplo, na confissão) as únicas substitutas" (Freud, 1893/1974, p. 14). Freud deixa claro, portanto, que a palavra é um substituto do ato.

Em 1914, no texto "Recordar, repetir e elaborar", Freud (1914/1974) utiliza o termo agirien para distinguir a rememoração e a repetição em ato. Aponta para o fato de que o ato é uma manifestação do inconsciente, ou seja, o paciente não sabe que está repetindo em ato. Para o autor, existem casos em que o paciente não recorda o fato que esqueceu, mas o expressa pela atuação (acts it out). Ele o reproduz não como lembrança, mas como ação, repete-o sem saber o que está repetindo. Freud nos dá o exemplo de um paciente desafiador em relação à autoridade dos pais e que se comportava da mesma forma com seu médico.

O agirien freudiano foi traduzido pelos psicanalistas ingleses por acting out, respeitando sua dualidade, já que o verbo to act out significa tanto representar uma peça, deixar ver, mostrar, como também agir, tomar medidas. O termo foi retomado posteriormente pelos psicanalistas franceses.

Em 1962, Lacan propõe uma distinção entre o acting out e a passagem ao ato. Como o acting out é algo que essencialmente se mostra para o Outro, uma mostração velada - não velada em si, mas velada para o próprio sujeito -, para Lacan, este seria, então, da ordem da evitação da angústia e, assim como o sintoma, porta uma mensagem em que há a revelação de um resto, daquilo que sobra, daquilo que está colocado como objeto $a$-objeto resto e, ao mesmo tempo, objeto causana relação do sujeito com seu próprio fantasma: $\$<>$ a.

No acting out, o sujeito não formula uma queixa, não se pergunta sobre o sentido de seu ato, não faz nenhuma subjetivação. Ele simplesmente age e se deixa ver. O sujeito não sai de cena; ele faz uma interpelação ao Outro. Trata-se de um ato que pede interpretação, contudo a interpretação não produz muito efeito. Lacan afirma que é o início da transferência, nomeando-a "transferência selvagem": "O acting out sem análise é a transferência" (Lacan, 1962-1963/2005, p. 140). Podemos, então, nos perguntar se o fato de Hannah pegar todos os objetos que fizeram parte do seu ritual de autoextermínio na farmácia de seus pais não seria algo do estatuto de um acting out, de uma interpelação ao Outro, de se "deixar ver"; uma convocação para que algo venha do campo do Outro.

7 Esses atos foram muito bem desdobrados no livro de Sônia Alberti, Esse sujeito adolescente.
O psicanalista francês ainda discute a função do acting out em relação à ética do analista. Quando acontece em análise, o acting out seria uma resposta à intervenção do analista ou a algo que ele não conseguiu escutar: "Esses atos são mensagens que informam sobre a função do desejo do analista e sobre a responsabilidade que lhe cabe pelo fato de ocupar esse lugar na transferência" (Vidal, 1993, p. 212). Seria quando o analista, em sua escuta, reduz o campo do desejo à demanda.

A passagem ao ato, por sua vez, é um termo que faz parte do vocabulário psiquiátrico francês e que significa uma ação na qual o sujeito se precipita, uma ação que o ultrapassa, como, por exemplo, o delito, a agressão ou o suicídio. A passagem ao ato não pede nada. Não se mostra. É um corte radical no qual o sujeito sai de cena e rompe sua relação com o universo simbólico. É decisivo e acontece sem cálculo ou premeditação. É uma saída da angústia, podendo propiciar uma retificação subjetiva ou, no caso de uma psicose, uma estabilização.

Na passagem ao ato, a saída é radical; não há demanda, não há retorno. Há ali o máximo de embaraço do sujeito, conforme demonstrado no esquema proposto por Lacan: "a passagem ao ato está do lado do sujeito na medida em que este aparece apagado ao máximo pela barra. ... ele se precipita e despenca fora da cena" (Lacan, 1962-1963/2005, p. 129). A estrutura da passagem reside na saída do sujeito da cena e é da ordem do deixar-se cair (laisser tomber ${ }^{8}$ ), do abandonar-se e quedar como objeto. Portanto seria uma saída para a angústia no máximo do embaraço do sujeito. $\mathrm{O}$ autor adverte, ainda, que "tudo o que é acting out é o oposto da passagem ao ato" (Lacan, 1962-1963/2005, p. 36), visto que, no primeiro, trata-se de subir no palco e, no segundo, trata-se do deixar-se cair.

Para Lacan (1957-1958/1999), a beleza horrenda do suicídio reside no fato de que é pela própria extinção do corpo que o suicida produz uma marca indelével no mundo simbólico de seus entes. Ao provocar uma ruptura com os equívocos do significante, uma interrupção de seus deslizamentos, o sujeito deixa sua marca como signo:

Quando abole a si mesmo, torna-se mais signo do que nunca. A razão disso é simples: é precisamente a partir do momento em que o sujeito morre que ele se torna, para os outros, um signo eterno, e os suicidas mais que os outros. É por isso mesmo que o suicídio tem uma beleza horrenda, que o faz tão terrivelmente condenado pelos homens, e também uma beleza contagiosa, que dá margem àquelas epidemias de suicídio que são o que há de mais real na experiência. (Lacan, 1957-1958/1999, p. 254) 


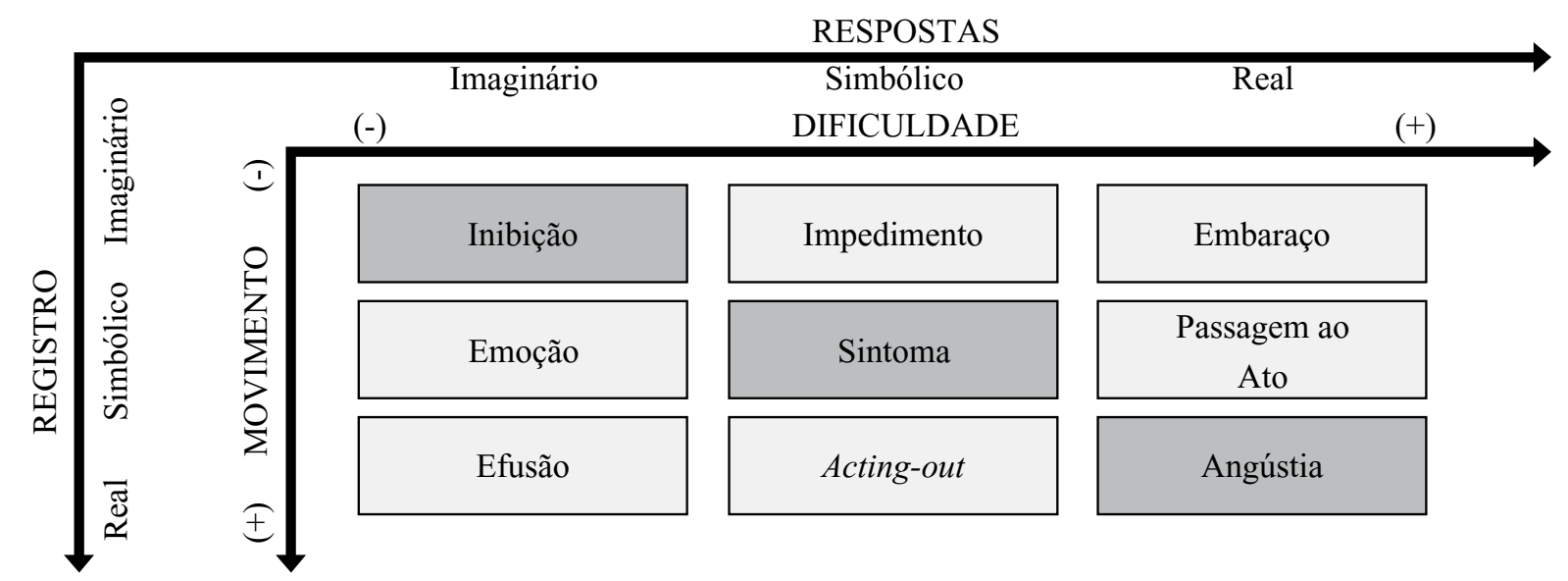

Figura 1. Esquema duplicado com a dimensão dos registros e das respostas, segundo Calazans (2015).

Como já ressaltamos, havia em Hannah um sentimento de invisibilidade, um afrouxamento do vínculo com os pais, para usar os termos de Freud, que não encontrou reenlaçamento nem na escola, nem nos laços amorosos, nem nos sociais. Além disso, podemos pensar, com Lacan (1975-1976/2007), que ela não consegue amarrar os três registros em um quarto elo que pudesse dar ela um novo lugar. Hannah sai do atendimento com o conselheiro mais angustiada do que entrou e encontra uma saída radical: uma passagem ao ato por meio do qual se marca como signo na vida das pessoas de suas relações. Não há mais deslocamento possível; nada seria a mesma coisa para os envolvidos. As fitas cumprem bem esse papel. Elas produzem uma marca em cada um dos treze personagens, uma marca indelével muito difícil de ser deslocada, daí o seu lugar de signo, do lugar que ocuparam nos motivos que conduziram Hannah ao suicídio.

De acordo com Lacan (1967-1968/1986), a eficácia do ato tem relação com aquilo que atinge o simbólico:

não há ação alguma que não se apresente, de saída e, antes de mais nada, com uma ponta significante. Esta sua ponta significante é justo o que caracteriza $o$ ato, e sua eficiência de ato nada tem a ver com a eficácia de um fazer" (Lacan, 1967-1968/1986).

Nessa mesma linha, Alberti (1996) nos advertirá que "a passagem ao ato pode ser carregada de revelação", já que possui uma "ponta de significante", sendo isso facilmente verificável nas cartas tão frequentemente deixadas pelos suicidas e também nas fitas deixadas por Hannah. Nesse ato há algo do sujeito que escapa da simbolização e ele se identifica com a posição de objeto.

Assim, é nessa posição caída como objeto que Hannah sai da cena da vida. Há um ponto de desligamento, de desresponsabilização do próprio sujeito com suas questões. É muito esclarecedor que a primeira temporada termine anunciando a tentativa de suicídio de Alex, um adolescente cujo pai policial, encarnando o lugar da lei, exime de prestar depoimento no processo de julgamento acerca das causas do suicídio de Hannah. É inevitável perceber que é devastador para esse jovem não se responsabilizar pelo que lhe cabe.

\section{Considerações finais}

Para finalizar, é importante retomarmos as questões iniciais: É possível escutar os indícios do suicídio? Muitas vezes, sim. Os jovens nos darão muitas dicas por meio de seus silêncios excessivos e de seus atos, que têm uma função e querem dizer alguma coisa.

O que fazer? Para quem os escuta, é importante dar um bom lugar à palavra, levar a fala do sujeito ao pé da letra, independentemente da estrutura clínica. Parece-nos fundamental, ainda, dilatar o tempo de compreensão do sujeito para evitar, assim, a precipitação num ato mais radical. Dar lugar à palavra é também um modo de o sujeito sair da invisibilidade. Isso é válido também para as instituições que podem estar atentas à flexibilização dos protocolos para que o jovem possa deles lançar mão quando estiver preparado para sustentar seus efeitos, efeitos de responsabilização fundamentais para a ligação com a vida e com os laços sociais.

Assim, não se trata de impedir nem de analisar nos moldes de uma interpretação o risco do suicídio, mas, antes, de interrogar sobre sua temporalidade, especialmente sobre as coordenadas do tempo anterior. Pode-se fazer uma construção acerca de sua estrutura e dos seus efeitos de retificação e transformação, abrindo condições para que pontes e passagens de uma posição a outra possam ser feitas. 


\section{Adolescence, acts and risk of suicide}

Abstract: This article discusses suicide among adolescents, using the television series 13 reasons why as methodological strategy to further analyze what is at stake in the relations between adolescence, acts and the risk of suicide. To accomplish a thorough comprehension of the matter, we reflect on adolescence based on Freudian and Lacanian theoretical elaborations, emphasizing their tendency to act out and the risky behaviors that characterize this stage of life. The text also makes a distinction between acting out and Lacan's concept of passage to the act and discusses how the analyst should clinically respond to adolescents who express any sort of suicidal ideas.

Keywords: adolescence, suicide, psychoanalysis, acting out, passage to the act.

\section{Adolescence, actes et le risque de suicide}

Résumé : Cet article aborde la problématique du risque de suicide à l'adolescence, en utilisant la série Les 13 pourquoi comme ressource méthodologique pour décanter les enjeux de la relation entre l'adolescence, les actes et le risque de suicide. Afin de mieux comprendre le thème, les auteurs comprennent l'adolescence à partir du cadre théorique de la psychanalyse de Freud et Lacan, en soulignant la tendance à l'acte de l'adolescence et les comportements à risque caractéristiques de cette étape de la vie. Le texte fait également la distinction entre acting out et passage à l'acte et propose une discussion sur la gestion clinique de l'analyste qui écoute les idées suicidaires d'un adolescent.

Mots-clés : adolescence, suicide, psychanalyse, acting out, passage à l'acte.

\section{Adolescencia, actos y el riesgo de suicidio}

Resumen: Este artículo discute el problema del riesgo de suicidio en la adolescencia, utilizando la serie Por trece razones como recurso metodológico para dar a conocer qué está en juego en la relación entre la adolescencia, los actos y el riesgo de suicidio. Para una comprensión más profunda del tema, las autoras realizan una lectura de la adolescencia a partir del marco teórico del psicoanálisis de Freud y Lacan, resaltando la tendencia al actuar de la adolescencia y los comportamientos de riesgo característicos de esa etapa de la vida. El texto traza, además, una distinción entre acting out y pasaje al acto y propone discutir sobre el manejo clínico del analista que escucha una ideación suicida de un adolescente.

Palabras clave: adolescencia, suicidio, psicoanálisis, acting-out, pasaje al acto.

\section{Referências}

Alberti, S. (1996). Esse sujeito adolescente. Rio de Janeiro, RJ: Relume-Dumará.

Bauman, Z. (2007). Vida líquida. Rio de Janeiro, RJ: Zahar.

Breton, D. (2017). Uma breve história da adolescência. Belo Horizonte, MG: Editora PUC Minas.

Calazans, R. (2015). Sobre a psicopatologia dos atos. Revista Psicologia Clínica, 27(1), 123-136.

Calligaris, C. (2000). Adolescência. São Paulo, SP: Publifolha.

Debord, G. (2000). Sociedade do espetáculo. Rio de Janeiro, RJ: Contraponto.

Erikson, E. (1976). Identidade, juventude e crise. Rio de Janeiro, RJ: Zahar. (Trabalho original publicada em 1968)

Freud, S. (1974). Sobre o mecanismo psíquico dos fenômenos histéricos: uma conferência. In Edição standard brasileira das obras psicológicas completas de Sigmund Freud (J. Salomão, Trad., Vol. 3, pp. 33-47). Rio de Janeiro, RJ: Imago. (Trabalho original publicado em 1893)

Freud, S. (1974). Contribuições para uma discussão acerca do suicídio. In Edição standard brasileira das obras psicológicas completas de Sigmund Freud (J. Salomão, Trad., Vol. 11, pp. 217-218). Rio de Janeiro, RJ: Imago. (Trabalho original publicado em 1910)

Freud, S. (1974). Recordar, repetir, elaborar. In Edição standard brasileira das obras psicológicas completas de Sigmund Freud (J. Salomão, Trad., Vol. 12, pp. 145156). Rio de Janeiro, RJ: Imago. (Trabalho original publicado em 1914)

Lacadée, P. (2007, 16 de junho). O risco da adolescência. Estado de Minas, Caderno Pensar, p. 3. 
Lacadée, P. (2011). O despertar e o exílio: ensinamentos psicanalíticos da mais delicada das transições, a adolescência. Rio de Janeiro, RJ: Contracapa.

Lacan, J. (1986). Seminário, libro 15: el acto psicoanalítico, 1967-1968. Buenos Aires: Paidós. Não paginado.

Lacan, J. (1998). A direção do tratamento e os princípios de seu poder. In Escritos. Rio de Janeiro, RJ: Zahar. (Trabalho original publicado em 1958)

Lacan, J. (1999). O seminário, livro 5: as formações do inconsciente, 1957-1958. Rio de Janeiro, RJ: Zahar.

Lacan, J. (2003). Televisão. In Outros escritos. Rio de Janeiro, RJ: Zahar. (Trabalho original publicado em 1974)

Lacan, J. (2005). O seminário, livro 10: a angústia, 19621963. Rio de Janeiro, RJ: Zahar.

Lacan, J. (2007). O seminário, livro 23: o sinthoma, 19751976. Rio de Janeiro, RJ: Zahar.

Le Breton, D. (2009). Condutas de risco: dos jogos de morte ao jogo de viver. Campinas, SP: Autores Associados.

Le Breton, D. (2017). Uma breve história da adolescência. Belo Horizonte, MG: Editora PUC Minas.

Miller, J., \& Milner, J-C. (2006). Você quer mesmo ser avaliado? Barueri, SP: Manole.

Nassau, C. R., Couto, D. P., Guerra, A. M., Capanema, C. A., \& Lima, V. M. (2018). Consequências subjetivas da nominação na adolescência e sua relação com o autor de ato infracional. Colóquio Internacional Adolescências e Leis, Seminário Clínico Adolescentes em Tempos de Guerra, 10. Belo Horizonte, MG: Centro de Atividades Didáticas de Ciências Humanas, 2018.

Vorcaro, A., \& Capanema, C. (2011). Chicanas da travessia adolescente. Psicologia em Revista, 17(1), 82-99. Recuperado de https://bit.ly/339qkOK

Stevens, A. (2004). Adolescência, sintoma da puberdade. Revista Curinga, 20, 27-39.

Vidal, E. (1993). Passagem ao ato e acting out. Revista Letra Freudiana, 12(1), 21-221.

Wedekind, F. (2009). O despertar da primavera: uma tragédia infantil e Mine-Haha, ou Sobre a educação corporal das meninas. São Paulo, SP: Luzes no Asfalto. (Trabalho original publicado em 1891)

World Health Organization. (2014). Preventing suicide: a global imperative. Recuperado de https://bit.ly/3mmldUe

Yorkey, B. (Diretor). (2017). Thirteen reasons why. Scotts Valley: Netflix.

Recebido: $12 / 08 / 2019$

Aprovado: 01/09/2020 